Check for updates

Cite this: RSC Adv., 2018, 8, 11764

\title{
Morphology- and $\mathrm{pH}$-dependent peroxidase mimetic activity of nanoceria $\uparrow$
}

\begin{abstract}
Xiaoshu Wei, Xiaofeng Li, Yuqian Feng and Sen Yang (D)*
The peroxidase mimetic properties of nanoceria have attracted extensive attention in recent years. In this work, the peroxidase mimetic properties of $\mathrm{CeO}_{2}$ nanocrystals with different morphologies, namely, nanocubes and nanorods, were investigated. Two types of oxidative species, $\mathrm{HO}$ radicals and peroxidelike intermediates, were identified in the $\mathrm{CeO}_{2} / \mathrm{H}_{2} \mathrm{O}_{2}$ systems. The formation of these oxidative species is strongly dependent on the $\mathrm{pH}$ value and the morphology of the $\mathrm{CeO}_{2}$ nanocrystals. The origin of the peroxidase mimetic activity of nanoceria was mainly ascribed to the presence of $\mathrm{HO}^{*}$ under acidic conditions, whereas the peroxide-like species also played a major role under neutral and basic conditions. $\mathrm{CeO}_{2}$ nanorods with excellent redox properties and higher concentration of $\mathrm{Ce}^{3+}$ and oxygen vacancies were more favorable for the generation of both $\mathrm{HO}^{\circ}$ and peroxide-like intermediates than that of $\mathrm{CeO}_{2}$ nanocubes, exhibiting excellent peroxidase mimetic activity toward 2,2' -azino-bis(3ethylbenzothiazoline-6-sulfonic acid) (ABTS), methylene blue (MB), and congo red (CR) in the presence of $\mathrm{H}_{2} \mathrm{O}_{2}$.
\end{abstract}

Received 21st January 2018

Accepted 21st March 2018

DOI: $10.1039 / \mathrm{c} 8 \mathrm{ra00622a}$

rsc.li/rsc-advances oxidation ability of nanoceria to some brown peroxide-like intermediates, ${ }^{17-20}$ which oxidize organic substances through intermolecular rearrangement. ${ }^{17,21,22}$ Although the exact structure of the active oxidative species responsible for the peroxidase mimetic activity of nanoceria have not been fully elucidated, it is believed that the $\mathrm{pH}$ value of the reaction medium has a significant influence on the peroxidase mimetic properties of nanoceria. ${ }^{8}$ Most studies have shown that nanoceria could be used as a peroxidase mimic in the $\mathrm{pH}$ range of 2.0-6.0,,$^{7,23}$ whereas a few studies have shown that the peroxidase mimetic activity of nanoceria could be observed at even higher $\mathrm{pH}$ values. ${ }^{\mathbf{1 3 2 1}}$ Therefore, further study is still needed to understand the relationship between the $\mathrm{pH}$ of the solution and the nature of the oxidative species and their oxidation abilities.

The peroxidase mimetic property of nanoceria originates from the redox cycles between $\mathrm{Ce}^{3+}$ and $\mathrm{Ce}^{4+} \cdot{ }^{15,24}$ Generally, the easier the redox cycles between $\mathrm{Ce}^{3+}$ and $\mathrm{Ce}^{4+}$, the better the peroxidase mimetic activity of nanoceria. ${ }^{12} \mathrm{Up}$ to now, several strategies including doping ceria with heteroatom ions such as $\mathrm{Zr}^{4+}$ and decreasing the particle size of the ceria particles has been used to enhance the peroxidase mimetic activity of ceria. ${ }^{12,17,23}$ Zhou et al. reported that the redox performance of nanoceria could also be optimized by tuning the crystal planes exposed on the surfaces. ${ }^{25}$ Since then, a series of studies have been carried out to optimize the catalytic performance of nanoceria for various reactions by tuning the morphology of $\mathrm{CeO}_{2}$ nanocrystals. ${ }^{26-29}$ However, to the best of our knowledge, the influence of the exposed crystal facet on the peroxidase mimetic activity of nanoceria has only been reported in a recent paper, which found that the Fenton-like reactivity of $\mathrm{CeO}_{2}$
Beijing Key Laboratory of Farmland Soil Pollution Prevention and Remediation, College of Resources and Environmental Sciences, China Agricultural University, Beijing 100193, PR China. E-mail: syang@cau.edu.cn; Tel: +86 1062733470

$\dagger$ Electronic supplementary information (ESI) available. See DOI: 10.1039/c8ra00622a 
nanocrystal was related to their exposed facets. ${ }^{30}$ Therefore, it is worth applying nanoceria with different morphologies as peroxidase mimetics to optimize the catalytic activity and understand the underlying mechanisms of the nanoceria mimic enzyme.

In this work, $\mathrm{CeO}_{2}$ nanocubes and nanorods were prepared by a hydrothermal method and their peroxidase mimetic properties were investigated under both acidic and basic conditions. Our studies revealed a strong morphologydependent peroxidase mimetic activity of nanoceria. The nature of the active oxidative species at different $\mathrm{pH}$ values and their oxidation abilities were investigated to gain a deep understanding of the mechanism of the peroxidase-mimetic activity of nanoceria.

\section{Experiments}

\subsection{Materials}

$\mathrm{Ce}\left(\mathrm{NO}_{3}\right)_{3} \cdot 6 \mathrm{H}_{2} \mathrm{O}, \mathrm{NaOH}, \mathrm{HCl}, \mathrm{H}_{2} \mathrm{O}_{2}(30 \%, \mathrm{w} / \mathrm{w}), n$-butyl alcohol, methylene blue (MB) and congo red (CR) were purchased from Sinopharm Chemical Reagent Co. Ltd (Shanghai, China). Catalase, 2,2'-azino-bis(3-ethylbenzothiazoline-6-sulfonic acid) (ABTS) and 5,5-dimethyl-1-pyrroline $N$-oxide (DMPO) were obtained from Sigma-Aldrich Co. LLC. (Saint Louis, USA). All reagents were of analytical reagent grade and were used without further purification.

\subsection{Synthesis of $\mathrm{CeO}_{2}$ nanocubes and $\mathrm{CeO}_{2}$ nanorods}

$\mathrm{CeO}_{2}$ nanocatalysts were synthesized through a hydrothermal process. ${ }^{25,31}$ Typically, $\mathrm{Ce}\left(\mathrm{NO}_{3}\right)_{3} \cdot 6 \mathrm{H}_{2} \mathrm{O}(1.5 \mathrm{~g})$ was dissolved in distilled water, and an appropriate amount of $10 \% \mathrm{NaOH}$ solution was rapidly added to give a final $\mathrm{NaOH}$ concentration of approximately $2.0 \mathrm{M}$. After stirring for approximately $15 \mathrm{~min}$, the slurry (approximately $40 \mathrm{~mL}$ ) was placed into a $50 \mathrm{~mL}$ Teflon-sealed autoclave and heated. The morphology of the asprepared nanoceria depended on the hydrothermal temperature and reaction time, that is, nanocubes were formed by heating at $180^{\circ} \mathrm{C}$ for $24 \mathrm{~h}$ and nanorods were formed by heating at $120^{\circ} \mathrm{C}$ for $12 \mathrm{~h}$. After cooling, the final product was collected by filtration, washed with deionized water, and then dried at $60{ }^{\circ} \mathrm{C}$.

\subsection{Catalyst characterization}

The size and morphology of the nanoceria was characterized with a JEM-2100F high-resolution transmission electron microscope (HRTEM, JEOL, Japan). The powder X-ray diffraction (XRD) patterns were obtained on an D8 Advance X-ray diffractometer (Bruker, Germany) with Ni-filtered $\mathrm{Cu} \mathrm{K} \alpha$ radiation $(\lambda=0.1541 \mathrm{~nm})$. The Brunauer-Emmett-Teller (BET) surface area was evaluated from nitrogen adsorption-desorption data recorded at $77 \mathrm{~K}$ using a model NOVA 3200e automated gas sorption system (Quantachrome, USA). X-ray photoelectron spectra (XPS) measurements were performed on an ESCALAB 250Xi high-performance electron spectrometer (Thermo Fisher, USA) using monochromatized $\mathrm{Al} \mathrm{K} \alpha(h \nu=$ $1486.6 \mathrm{eV}$ ) as the excitation source. Raman spectra were collected by a Raman spectrometer (Renishaw inVia, UK) with a laser wavelength of $514.5 \mathrm{~nm}$. Hydrogen temperatureprogrammed reduction $\left(\mathrm{H}_{2}\right.$-TPR) was conducted with a ChemiSorb 2750 apparatus (Micromeritics, USA) equipped with a TCD detector. TPR was performed by heating the nanoceria samples $(50 \mathrm{mg})$ at $10{ }^{\circ} \mathrm{C} \mathrm{min}^{-1}$ from $50-700{ }^{\circ} \mathrm{C}$ in a $5 \mathrm{vol} \% \mathrm{H}_{2}-\mathrm{N}_{2}$ mixture with a flow rate of $25 \mathrm{~mL} \mathrm{~min}^{-1}$.

\subsection{Electron paramagnetic resonance (EPR) measurements}

To monitor the potential radicals formed in the nanoceria/ $\mathrm{H}_{2} \mathrm{O}_{2}$ system, DMPO was used as the spin trap and EPR spectra were recorded using a JES-FA200 EPR spectrometer (X-band) with dual cavities (JEOL, Japan). Typical parameters were as follows: modulation frequency, $100 \mathrm{kHz}$; microwave frequency, 9.05 GHz; sweep width, $50 \mathrm{G}$; EPR microwave power, $3 \mathrm{~mW}$; modulation amplitude, $1 \mathrm{G}$; time constant, $0.03 \mathrm{~s}$; and sweep time, 2 min.

\subsection{Peroxidase mimetics activity of nanoceria}

The catalytic reaction was performed at $25^{\circ} \mathrm{C}$ using $1 \mathrm{~g} \mathrm{~L}^{-1} \mathrm{CeO}_{2}$ with $2 \mathrm{mM}$ ABTS, $15 \mathrm{mg} \mathrm{L}^{-1} \mathrm{MB}$ or $70 \mathrm{mg} \mathrm{L}^{-1} \mathrm{CR}$ as substrate and $20 \mathrm{mM} \mathrm{H}_{2} \mathrm{O}_{2}$, unless otherwise stated. Generally, catalyst powder was added into a conical flask containing an aqueous solution of the substrate. Then, a $\mathrm{H}_{2} \mathrm{O}_{2}$ solution was added to initiate the oxidation reaction. To avoid the influence of ions on the nanoceria activity, ultrapure water was used in the test, and the initial $\mathrm{pH}$ of the reaction system was adjusted using $0.1 \mathrm{M}$ $\mathrm{HCl}$ and $0.1 \mathrm{M} \mathrm{NaOH}$ solution. The concentration of organics and $\mathrm{H}_{2} \mathrm{O}_{2}$ in supernatant was analyzed by using a UV-vis spectrophotometer (Beijing Purkinje General, China). The maximum wavelengths $\left(\lambda_{\max }\right)$ of $\mathrm{H}_{2} \mathrm{O}_{2}, \mathrm{ABTS}^{{ }^{+}}$, $\mathrm{MB}$ and $\mathrm{CR}$ are 240, 734, 664 and $497 \mathrm{~nm}$, respectively.

\section{Results and discussion}

\subsection{Characterization of $\mathrm{CeO}_{2}$ nanocubes and nanorods}

The morphologies of the as-prepared samples were examined by transmission electron microscopy (TEM). The $\mathrm{CeO}_{2}$ nanocubes had uniform cubic shapes with a size of $20-30 \mathrm{~nm}$ (Fig. 1a). The HRTEM image in Fig. 1b shows an interplanar spacing of $0.27 \mathrm{~nm}$, corresponding to the (200) lattice fringe of $\mathrm{CeO}_{2}$, which indicates that the nanocubes were mainly enclosed by the (100) facets. ${ }^{31}$ As shown in Fig. 1c, $\mathrm{CeO}_{2}$ nanorods had diameters of approximately $15-20 \mathrm{~nm}$ and lengths of $100-200 \mathrm{~nm}$. The HRTEM analysis (Fig. 1d) revealed that the nanorods were single-crystalline and their growth direction was (110). This was consistent with the previously reported results that nanorods expose their (110) and (100) facets. ${ }^{25}$

The XRD patterns of the $\mathrm{CeO}_{2}$ nanocubes and nanorods are shown in Fig. 2a. All the diffraction peaks of both samples can be indexed to the pure fluorite structure of $\mathrm{CeO}_{2}$ (JCPDS 340394). ${ }^{28}$ The sharper peaks of the nanocubes indicated their higher crystallinity and bigger crystallite size than those of the nanorods ${ }^{26}$ which was consistent with the TEM and HRTEM analysis. The specific surface areas of the nanocerias were measured by a nitrogen gas adsorption-desorption isotherm 


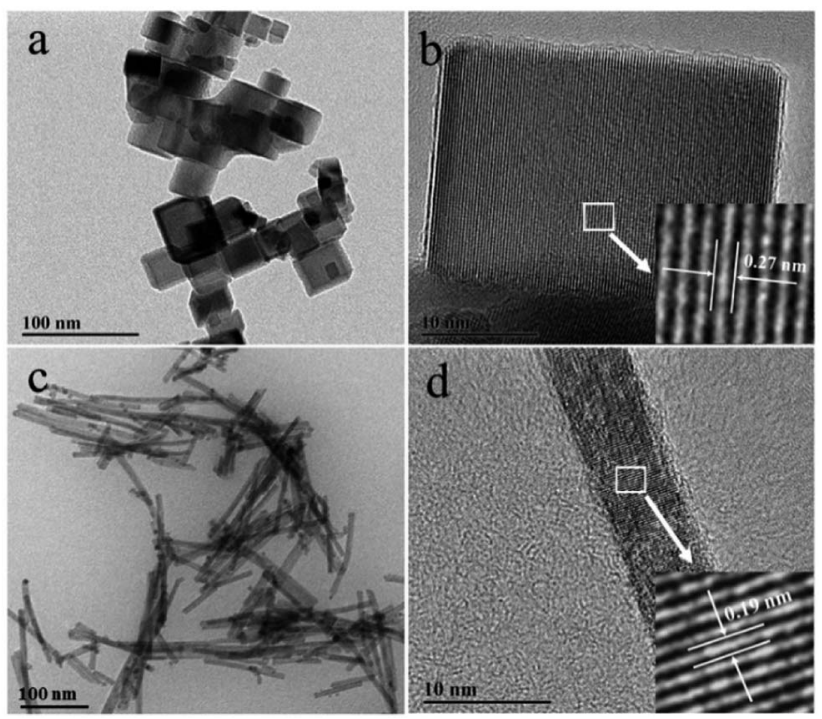

Fig. 1 TEM images of (a) $\mathrm{CeO}_{2}$ nanocubes and (c) nanorods, and HRTEM images of (b) $\mathrm{CeO}_{2}$ nanocubes and (d) nanorods.
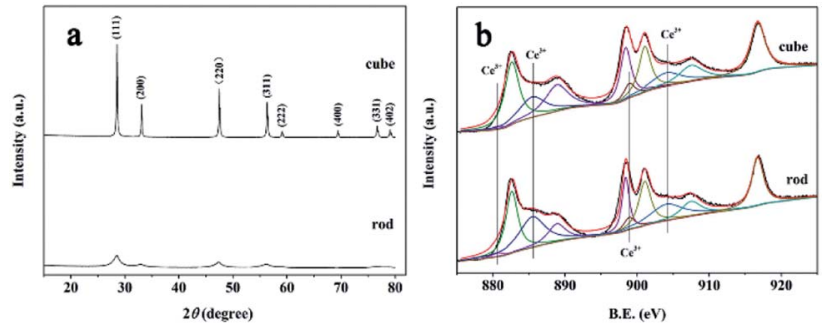

Fig. 2 XRD patterns (a) and Ce3d XPS spectra (b) of $\mathrm{CeO}_{2}$ nanocubes and nanorods.

and calculated by the BET method. The nanorods exhibited a larger specific surface area $\left(89.9 \mathrm{~m}^{2} \mathrm{~g}^{-1}\right)$ than that of the nanocubes $\left(39.7 \mathrm{~m}^{2} \mathrm{~g}^{-1}\right)$.

The valence state of the Ce ions in the nanocerias was determined by XPS and the results are shown in Fig. 2b. The Ce3d XPS spectra revealed that a mixed valence state $\left(\mathrm{Ce}^{3+}\right.$ and $\left.\mathrm{Ce}^{4+}\right)$ was present and most of the Ce ions were $\mathrm{Ce}^{4+}$ in both nanoceria samples..$^{32}$ However, the peaks attributed to $\mathrm{Ce}^{3+}$ in the nanorods, were clearly stronger than those for the nanocubes, as marked in Fig. 2 b, indicating that more $\mathrm{Ce}^{3+}$ was on the surface of the nanorods. ${ }^{33,34}$ The Ce3d spectra were fitted using PeakFit software to calculate the $\mathrm{Ce}^{3+}$ concentration on the surface of both samples. The relative concentration of $\mathrm{Ce}^{3+}$ on the surface of the nanorods was $34.7 \%$, which was much larger than that of the nanocubes (23.3\%). The presence of more $\mathrm{Ce}^{3+}$ indicated that there were more oxygen vacancies in the $\mathrm{CeO}_{2}$ nanorods, which was further verified by Raman analysis.

Fig. 3a displays the Raman spectra of the samples; two bands were observed for both samples. The presence of the prominent $F_{2 g}$ vibrational mode band at approximately $460 \mathrm{~cm}^{-1}$ was ascribed to the symmetric mode of the oxygen atoms around the cerium ions. ${ }^{28}$ Compared with that of $\mathrm{CeO}_{2}$ nanorods, the Raman band of the nanocubes displayed a clear increase in
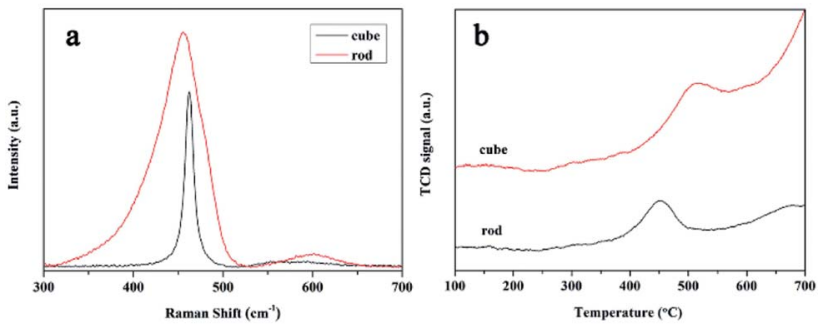

Fig. 3 (a) Raman spectra and (b) $\mathrm{H}_{2}$-TPR profiles of $\mathrm{CeO}_{2}$ nanocubes and nanorods.

symmetry and a decrease in the full width at half maximum, along with an evident shift towards higher wave numbers. This was attributed to the higher degree of crystallinity and larger crystallite size of the nanocubes. ${ }^{35,36}$ The weak band at approximately $590 \mathrm{~cm}^{-1}$ was associated to the defect-induced mode (D) ${ }^{35}$ The degree of defect sites on $\mathrm{CeO}_{2}$ was estimated using the relative intensity of $\mathrm{D} / \mathrm{F}_{2 \mathrm{~g}} \cdot{ }^{28,36}$ The $\mathrm{D} / \mathrm{F}_{2 \mathrm{~g}}$ ratio of the $\mathrm{CeO}_{2}$ nanorods was 0.056 , which was higher than that of the nanocubes (0.023). This implied that $\mathrm{CeO}_{2}$ nanorods had more defect sites such as oxygen vacancies, which was consistent with the XPS results.

The presence of more $\mathrm{Ce}^{3+}$ and defects in $\mathrm{CeO}_{2}$ nanorods suggested that the nanorods could be more reducible than the nanocubes. Subsequently, the redox properties of the nanoceria samples were examined by $\mathrm{H}_{2}$-TPR. The TPR profiles (Fig. $3 \mathrm{~b}$ ) of both samples showed two reduction bands, one located below $580{ }^{\circ} \mathrm{C}$ and one above $600{ }^{\circ} \mathrm{C}$. The low-temperature reduction band is related to the surface oxygen reduction and is of particular interest in catalytic reactions..$^{32}$ The low-temperature peak position of the $\mathrm{CeO}_{2}$ nanorods was at $450{ }^{\circ} \mathrm{C}$, which was much lower than that of the nanocubes $\left(510^{\circ} \mathrm{C}\right)$, indicating that the $\mathrm{CeO}_{2}$ nanorods were much more reducible than the nanocubes. $^{28}$ The facile redox performance of the $\mathrm{CeO}_{2}$ nanorods indicated that the $\mathrm{CeO}_{2}$ nanorods should perform well as peroxidase mimetics.

\section{2 $\quad \mathrm{H}_{2} \mathrm{O}_{2}$ decomposition and probing the possible oxidative species}

The decomposition of $\mathrm{H}_{2} \mathrm{O}_{2}$ over $\mathrm{CeO}_{2}$ nanocubes and nanorods was first investigated from $\mathrm{pH} 3.0$ to 9.0. This set of data is for $20 \mathrm{mM} \mathrm{H}_{2} \mathrm{O}_{2}$ in the presence of $1 \mathrm{~g} \mathrm{~L}^{-1} \mathrm{CeO}_{2}$ at $25^{\circ} \mathrm{C}$. Fig. $4 \mathrm{a}$ shows the $\mathrm{H}_{2} \mathrm{O}_{2}$ concentration changes as a function of time. The decomposition of $\mathrm{H}_{2} \mathrm{O}_{2}$ in the presence of $\mathrm{CeO}_{2}$ follows first-order kinetics as previous reported (Fig. $\mathrm{S} 1 \dagger$ )..$^{14,37}$ The rate coefficients are given in Table S1. $\dagger$ It is clear that the effect of the $\mathrm{pH}$ on the decomposition of $\mathrm{H}_{2} \mathrm{O}_{2}$ over nanoceria is not obvious and only a slight increase in conversion can be observed with increasing pH from 3.0 to $9.0 .^{38}$ However, $\mathrm{CeO}_{2}$ nanorods display higher activity over all reactivity towards $\mathrm{H}_{2} \mathrm{O}_{2}$. When the amount of eliminated $\mathrm{H}_{2} \mathrm{O}_{2}$ was normalized to the surface area of nanocubes and nanorods, $\mathrm{CeO}_{2}$ nanorods still possessed higher level of activity (Fig. 4b).

It has been reported that nanoceria could facilitate the decomposition of $\mathrm{H}_{2} \mathrm{O}_{2}$ to produce $\mathrm{HO}^{*}$ through a series of reactions analogous to Fenton/Haber Weiss reactions: ${ }^{15,39,40}$ 

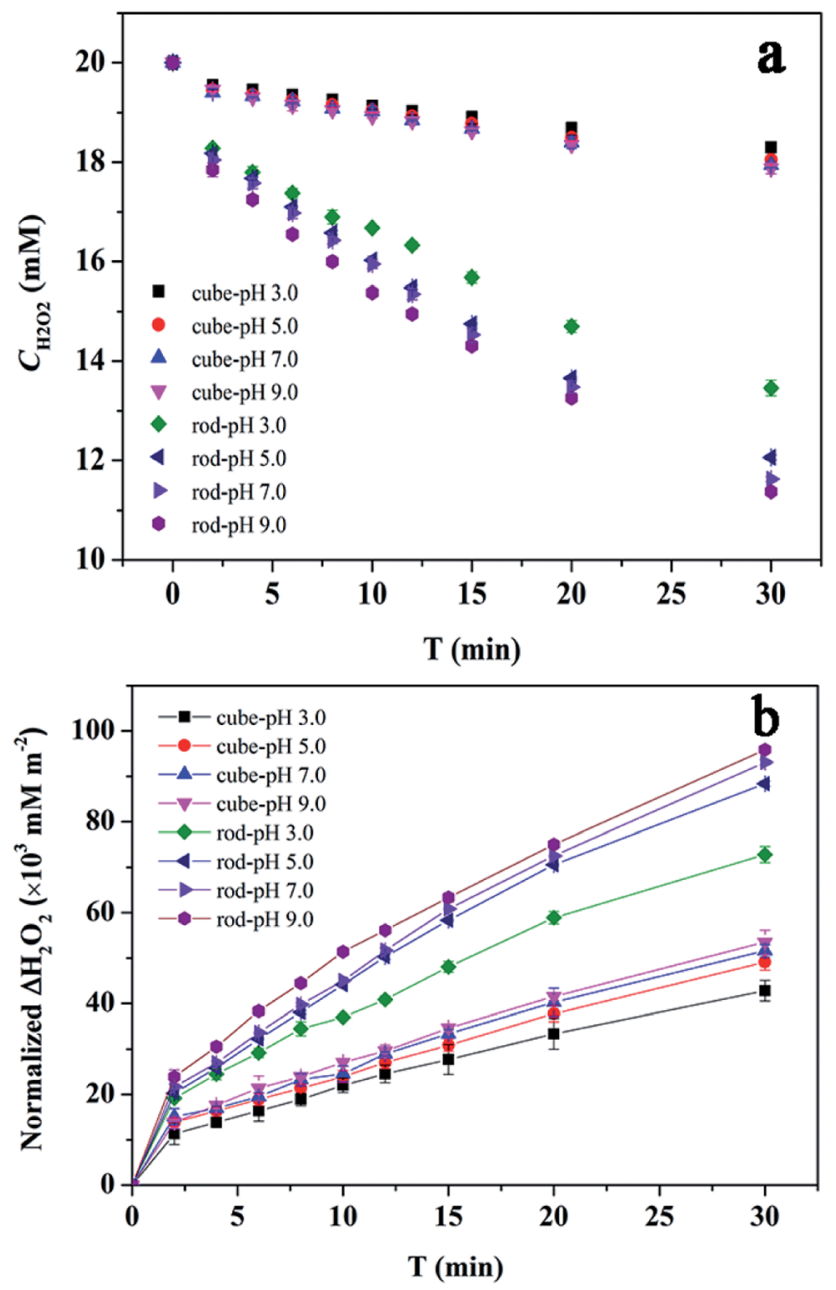

Fig. 4 Catalytic activity of $\mathrm{CeO}_{2}$ : (a) concentration changes of $\mathrm{H}_{2} \mathrm{O}_{2}$ as a function of reaction time and (b) the eliminated $\mathrm{H}_{2} \mathrm{O}_{2}$ was normalized to $\mathrm{CeO}_{2}$ surface area $\left(20 \mathrm{mM} \mathrm{H}_{2} \mathrm{O}_{2}, 1 \mathrm{~g} \mathrm{~L}^{-1} \mathrm{CeO}_{2}, 25^{\circ} \mathrm{C}\right.$ ).

$$
\begin{gathered}
\mathrm{Ce}^{3+}+\mathrm{H}_{2} \mathrm{O}_{2}+\mathrm{H}^{+} \rightarrow \mathrm{Ce}^{4+}+\mathrm{OH}^{\cdot}+\mathrm{H}_{2} \mathrm{O} \\
\mathrm{OH}^{\cdot}+\mathrm{H}_{2} \mathrm{O}_{2} \rightarrow \mathrm{HO}_{2}^{-}+\mathrm{H}_{2} \mathrm{O} \\
\mathrm{Ce}^{4+}+\mathrm{HO}_{2}^{-} \rightarrow \mathrm{O}_{2}+\mathrm{Ce}^{3+}+\mathrm{H}^{+}
\end{gathered}
$$

To probe the possible generation of $\mathrm{HO}^{\circ}$ during the catalytic decomposition of $\mathrm{H}_{2} \mathrm{O}_{2}$ over nanoceria, EPR was performed using the DMPO as a spin trap. As shown in Fig. 5, a 4-line EPR spectrum characteristic of DMPO-OH adducts was detected for a suspension of nanorods upon the addition of $\mathrm{H}_{2} \mathrm{O}_{2}$, but the intensity of the DMPO-OH signal decreased from $\mathrm{pH} 3.0$ to $\mathrm{pH}$ 9.0. Similar results were obtained for a suspension of nanocubes, except the intensity of the DMPO-OH peaks was significantly lower than those of the nanorods under the same conditions. These results clearly show that $\mathrm{HO}^{*}$ can be generated in the catalytic decomposition of $\mathrm{H}_{2} \mathrm{O}_{2}$ and the yield of $\mathrm{HO}^{\circ}$ is decreased with increasing $\mathrm{pH}$ from 3.0 to $9.0 .^{22,41}$ And $\mathrm{CeO}_{2}$ nanorods with better redox properties were more favorable for the generation of $\mathrm{HO}^{*}$ than their nanocube counterparts. Then the ability of the nanoceria to generate $\mathrm{HO}^{*}$ strongly depends on its redox properties. ${ }^{40}$

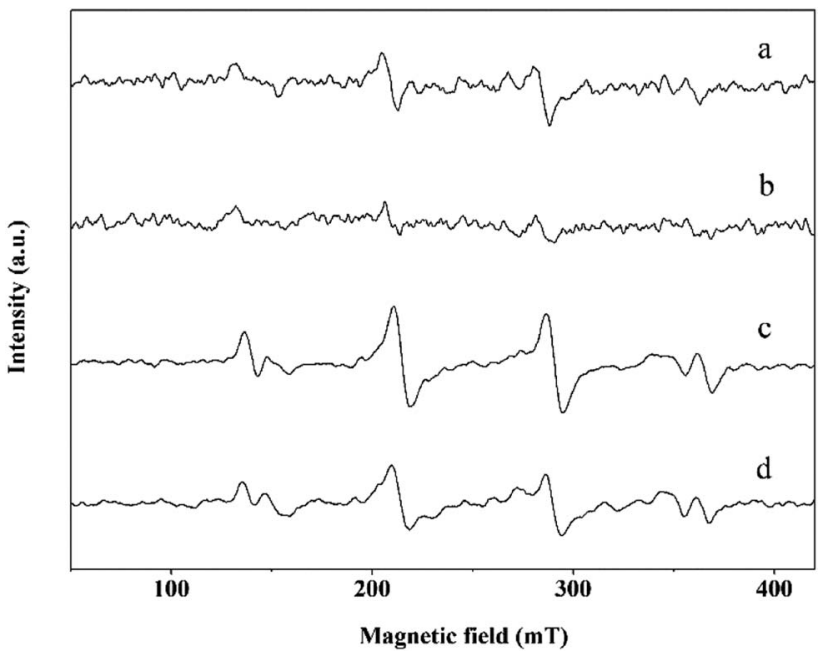

Fig. 5 DMPO spin trapping EPR spectra of $\mathrm{CeO}_{2} / \mathrm{H}_{2} \mathrm{O}_{2}$ system. Nanocubes $/ \mathrm{H}_{2} \mathrm{O}_{2}$ at pH 3.0 (a) and 9.0 (b); nanorods $/ \mathrm{H}_{2} \mathrm{O}_{2}$ at pH 3.0 (c) and 9.0 (d). The incubation time is $2 \mathrm{~min}$, and $\left[\mathrm{CeO}_{2}\right]=1 \mathrm{~g} \mathrm{~L}^{-1},\left[\mathrm{H}_{2} \mathrm{O}_{2}\right]$ $=20 \mathrm{mM}$.

It should be noted that a rapid color change was observed upon the addition of $\mathrm{H}_{2} \mathrm{O}_{2}$ into the nanoceria suspensions: the nanocubes suspension became light yellow and the nanorods suspension became deep yellow (Fig. 6). The color change was attributed to the formation of another type of oxidative species (the peroxide-like intermediates) from the reaction between $\mathrm{H}_{2} \mathrm{O}_{2}$ and $\mathrm{CeO}_{2} \cdot{ }^{12,19,38}$ The small variations in the color change of nanoceria from $\mathrm{pH} 3.0$ to 9.0 were almost completely imperceptible to the eye, indicating that the formation of peroxidelike intermediates was independent of the $\mathrm{pH}$ value. Compared with the suspension of the nanocubes $/ \mathrm{H}_{2} \mathrm{O}_{2}$, the deeper color of the nanorods/ $\mathrm{H}_{2} \mathrm{O}_{2}$ system indicated more

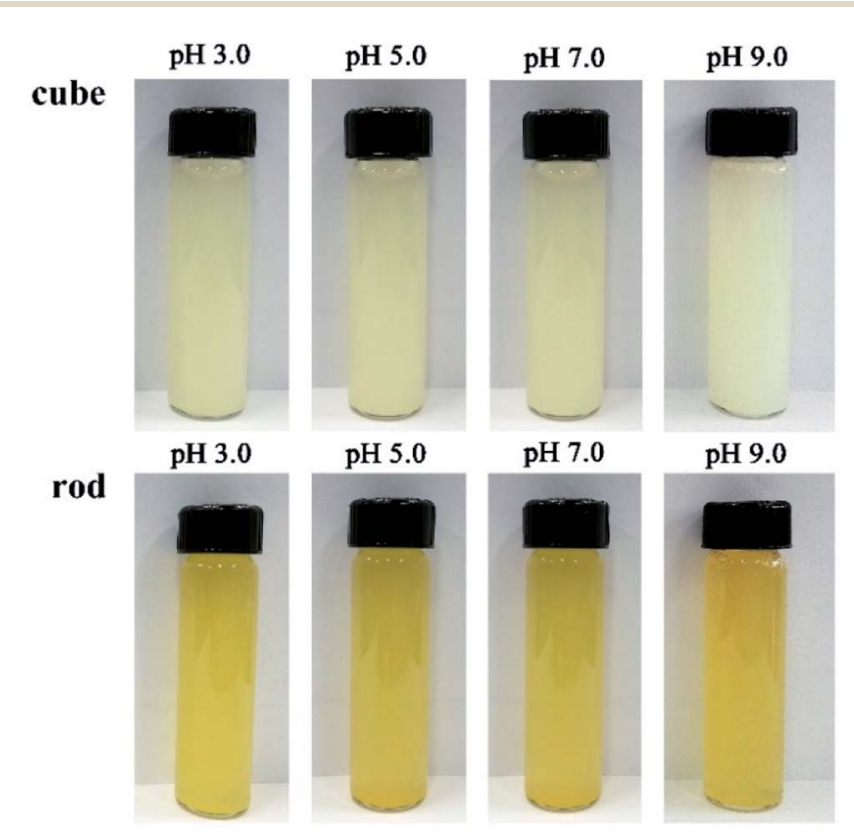

Fig. 6 Photographs of nanoceria suspensions after the addition of $\mathrm{H}_{2} \mathrm{O}_{2}$ at various $\mathrm{pH}\left(50 \mathrm{mM} \mathrm{H}_{2} \mathrm{O}_{2}, 0.5 \mathrm{~g} \mathrm{~L}^{-1} \mathrm{CeO}_{2}\right.$ ). 
peroxide-like species were generated owing to the presence of more $\mathrm{Ce}^{3+}$ and oxygen vacancies, as proved by XPS and Raman analysis. A generally accepted view is that the ease of $\mathrm{Ce}^{3+} / \mathrm{Ce}^{4+}$ redox cycles plays a significant role in the decomposition of $\mathrm{H}_{2} \mathrm{O}_{2}$ and the generation of peroxide-like intermediates. ${ }^{21}$ In this process, the rate of $\mathrm{Ce}^{3+}$ oxidation is much faster than that of $\mathrm{Ce}^{4+}$ reduction, and high concentration of $\mathrm{Ce}^{3+}$ would enhance the reducibility of ceria. ${ }^{32,38,42}$ Therefore, high peroxidase mimetic activity of ceria nanorods can be attributed to the high concentration of $\mathrm{Ce}^{3+}$ and the better reducibility.

The above results show that there were two types of oxidative species, namely $\mathrm{HO}^{*}$ and peroxide-like intermediates, which can be generated in the nanoceria/ $\mathrm{H}_{2} \mathrm{O}_{2}$ systems. The formation of these oxidative species was strongly dependent on the $\mathrm{pH}$ value and the morphology of the $\mathrm{CeO}_{2}$ nanocrystals, which determined the peroxidase mimetic performance of nanoceria.

\subsection{Peroxidase mimetic activity of $\mathrm{CeO}_{2}$ nanocubes and nanorods}

The peroxidase mimetic activity of the $\mathrm{CeO}_{2}$ samples was evaluated semiquantitatively by the oxidation of ABTS in the presence of $\mathrm{H}_{2} \mathrm{O}_{2}$ from $\mathrm{pH} 3.0$ to 9.0. ABTS is typically used as a horseradish peroxidase substrate, which develops a green color $\left(\mathrm{ABTS}^{\cdot+}\right)$ upon oxidation in aqueous solution. Control experiments showed that the color change of the systems was negligible without the presence of nanoceria or $\mathrm{H}_{2} \mathrm{O}_{2}$ (Fig. S2 $\dagger$ ). As shown in Fig. 7, a distinct and rapid change of the nanoceria/ $\mathrm{H}_{2} \mathrm{O}_{2}$ suspension to a green color was observed upon the addition of ABTS, indicating that nanoceria did exhibit high peroxidase-mimetic activity, as reported previously., ${ }^{70}$ Compared with the nanocubes, the nanorods exhibited a higher activity under the current conditions, which could be explained by the generation of more $\mathrm{HO}$ - and peroxide-like intermediates owing to their better redox property and high concentration of $\mathrm{Ce}^{3+}$ and oxygen vacancies. Moreover, it is evident that the color

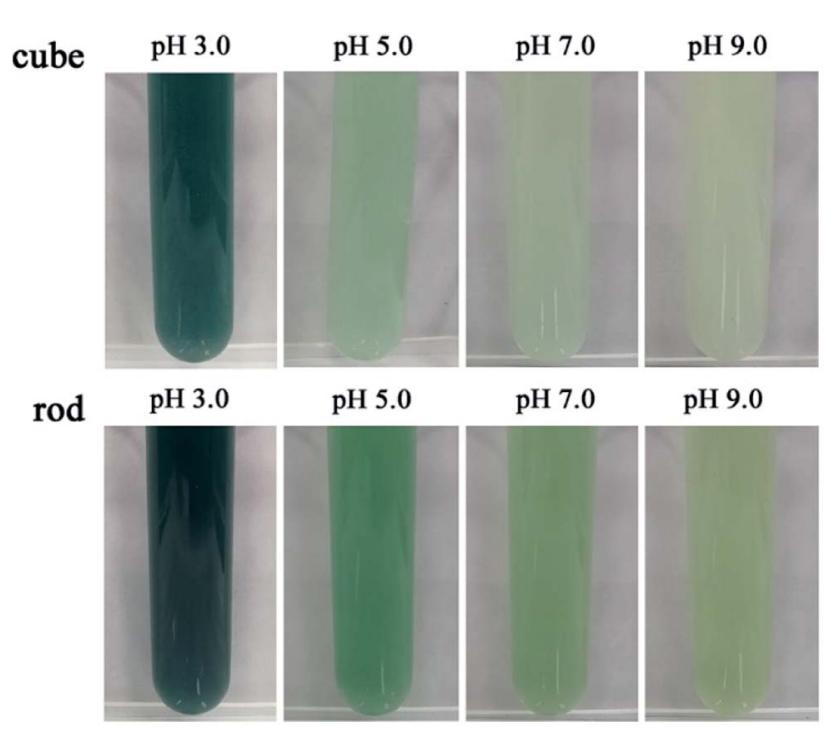

Fig. 7 The $\mathrm{pH}$ effect on the production of colored product owing to ABTS oxidation in the nanoceria $/ \mathrm{H}_{2} \mathrm{O}_{2}$ system $\left(0.2 \mathrm{~g} \mathrm{~L}^{-1} \mathrm{CeO}_{2}, 10 \mathrm{mM}\right.$ $\mathrm{H}_{2} \mathrm{O}_{2}, 5$ mM ABTS, $t: 2$ min). of the suspensions changes from dark green to lighter with $\mathrm{pH}$ value from 3.0 to 9.0, showing a strong $\mathrm{pH}$-dependent peroxidase mimetic activity of nanoceria. Nanoceria display higher peroxidase mimetic activity at acidic conditions and the timedependent UV-vis spectra of the oxidized product of ABTS $\left(\mathrm{ABTS}^{\circ+}\right)$ at room temperature are shown in Fig. 8. To further understand the peroxidase mimetic behaviors of the ceria nanocubes and nanorods, decolorization of MB and CR were carried out.

\subsection{Decolorization of $\mathrm{MB}$ and $\mathrm{CR}$ in nanoceria/ $/ \mathrm{H}_{2} \mathrm{O}_{2}$ system}

First, decolorization of $15 \mathrm{mg} \mathrm{L}^{-1} \mathrm{MB}$ with $1.0 \mathrm{~g} \mathrm{~L}^{-1}$ nanoceria and $20 \mathrm{mM} \mathrm{H}_{2} \mathrm{O}_{2}$ at $\mathrm{pH} 3.0$ was investigated. It turned out that the decolorization of $\mathrm{MB}$ over nanorods was $11.6 \%$ after $30 \mathrm{~min}$, while only $4.8 \%$ was achieved over nanocubes. To investigate the role of $\mathrm{HO}$ - and peroxide-like intermediates in the decolorization process, we performed this experiment by adding $200 \mathrm{mM} n$-butanol as a radical scavenger before the reaction was initiated. Excess $n$-butanol in solution can scavenge all the HOproduced in the $\mathrm{H}_{2} \mathrm{O}_{2}$ decomposition process and inhibit the degradation of $\mathrm{MB}^{40}$ As expected, the decolorization of MB was completely inhibited in the presence of $n$-butanol. This result verified that the peroxidase mimetic activity of nanoceria was mainly owing to the formation of $\mathrm{HO}$. under acidic conditions. ${ }^{13,14}$ It is well known that $\mathrm{HO}^{-}$exhibits high reactivity and can non-selectively oxidize most organic compounds at near diffusion-controlled rates under acidic condition. ${ }^{43}$ Although the peroxide-like intermediates were also present, it seemed they did not work. In fact, Chen et al. ${ }^{\mathbf{4 4}}$ and Hamoud et al. ${ }^{\mathbf{1 2}}$ reported that the peroxide-like intermediates were prone to decompose in to $\mathrm{HO}^{\circ}$ under acidic conditions. This can be used to explain the complete inhibition decolorization of $\mathrm{MB}$ in the presence of $n$-butanol.

Subsequently, the decolorization of $\mathrm{MB}$ at $\mathrm{pH} 9.0$ was carried out. Because of the strong adsorption on ceria arising under these conditions ( $\mathrm{pH}$ 9.0), both adsorption and oxidative degradation contributed to the total decolorization. After

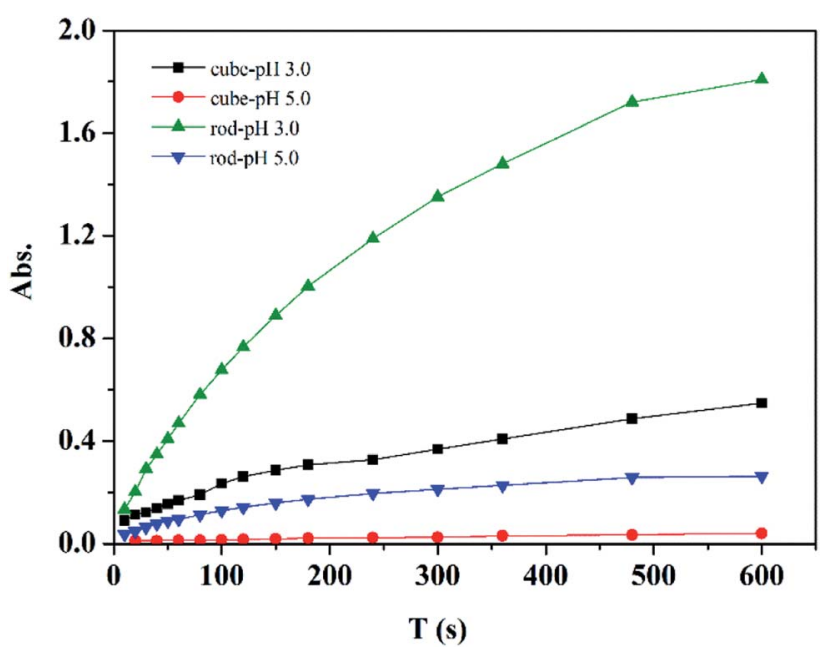

Fig. 8 Time-dependent absorbance changes at $734 \mathrm{~nm}$ of ABTS in different systems $\left(0.1 \mathrm{~g} \mathrm{~L}^{-1} \mathrm{CeO}_{2}, 5 \mathrm{mM} \mathrm{H}_{2} \mathrm{O}_{2}\right.$ and $\left.2 \mathrm{mM} \mathrm{ABTS}\right)$. 
eliminating the interference arising from adsorption, the degradation of MB was obtained (more information is provided in the $\mathrm{ESI}_{\dagger}^{\dagger}$ ). After $0.5 \mathrm{~h}$, the degradation of $\mathrm{MB}$ in the presence of $\mathrm{CeO}_{2}$ nanorods and nanocubes was only $5.3 \%$ and $3.4 \%$, respectively. These results suggested that nanoceria/ $\mathrm{H}_{2} \mathrm{O}_{2}$ system could degrade $\mathrm{MB}$ at $\mathrm{pH} 9.0$ but the peroxidase mimetic reactivity of nanoceria was much lower than that at $\mathrm{pH}$ 3.0. To further understand the peroxidase-mimetic activity of nanoceria under basic conditions, the degradation of CR, a typical anionic azodye, was investigated at $\mathrm{pH}$ 9.0. The $\mathrm{CR}\left(70 \mathrm{mg} \mathrm{L}^{-1}\right)$ could be completely degraded after $1 \mathrm{~h}$ in the presence of nanorods, whereas the degradation was only $8.2 \%$ in the presence of nanocubes. Interestingly, this time, the addition of $n$ butanol could not completely inhibit the degradation of both MB and CR under basic conditions, although the degradation rates of dye were decreased with a certain extent. For example, the complete degradation time of $\mathrm{CR}$ in nanorods $/ \mathrm{H}_{2} \mathrm{O}$ system was delayed from $1 \mathrm{~h}$ to $2.5 \mathrm{~h}$ upon addition of $n$-butanol. These results suggested that both $\mathrm{HO}$ - and the peroxide-like intermediates were acting as the oxidative species in the nanoceria/ $\mathrm{H}_{2} \mathrm{O}_{2}$ system under basic conditions. ${ }^{29}$ According to previous reports, under neutral and basic conditions, the peroxide-like intermediates can directly function as peroxidase-like active sites $^{\mathbf{2 3 , 4 5}}$ or induce an intermolecular rearrangement to achieve the oxidation of organics. ${ }^{21,22}$ Because oxidation ability of $\mathrm{HO}^{\circ}$ was much weaker under basic conditions than acidic conditions, ${ }^{12,46}$ the importance of the peroxide-like intermediates was raised.

\section{Conclusions}

Nanoceria possesses strong morphology- and pH-dependent peroxidase-like activity for the degradation of ABTS, MB and CR. Two types of oxidative species were generated in the nanoceria/ $\mathrm{H}_{2} \mathrm{O}_{2}$ systems, namely, $\mathrm{HO}^{\circ}$ and peroxide-like intermediates. Under acidic conditions, $\mathrm{HO}^{*}$ are primarily responsible for the peroxidase mimetic activity of nanoceria; under neutral and basic conditions, $\mathrm{HO}^{*}$ and peroxide-like intermediates are responsible for activity. Compared with $\mathrm{CeO}_{2}$ nanocubes, ceria nanorods exhibited a higher peroxidase activity owing to their excellent redox property and more $\mathrm{Ce}^{3+}$ and oxygen vacancies.

\section{Conflicts of interest}

There are no conflicts to declare.

\section{Acknowledgements}

The authors are grateful for the financial support provided by the National Natural Science Foundation of China (Grant No. 21476251).

\section{References}

1 M. Tamura and K. Tomishige, Angew. Chem., Int. Ed., 2015, 54,864 .
2 T. Montini, M. Melchionna, M. Monai and P. Fornasiero, Chem. Rev., 2016, 116, 5987.

3 A. Trovarelli, Catal. Rev.: Sci. Eng., 1996, 38, 439.

4 M. Das, S. Patil, N. Bhargava, J. F. Kang, L. M. Riedel, S. Seal and J. J. Hickman, Biomaterials, 2007, 28, 1918.

5 W. Lin, Y.-w. Huang, X.-D. Zhou and Y. Ma, Int. J. Toxicol., 2006, 25, 451.

6 C. Xu and X. G. Qu, NPG Asia Mater., 2014, 6, e90.

7 X. Jiao, H. J. Song, H. H. Zhao, W. Bai, L. C. Zhang and Y. Lv, Anal. Methods, 2012, 4, 3261.

8 Q. Y. Liu, Y. Y. Ding, Y. T. Yang, L. Y. Zhang, L. F. Sun, P. P. Chen and C. Gao, Mater. Sci. Eng., C, 2016, 59, 445-453.

9 X. M. Li, L. Sun, A. Q. Ge and Y. S. Guo, Chem. Commun., 2011, 47, 947.

10 L. F. Sun, Y. Y. Ding, Y. L. Jiang and Q. Y. Liu, Sens. Actuators, $B, 2017,239,848$.

11 H. Issa Hamoud, G. Finqueneisel and B. Azambre, J. Environ. Manage., 2017, 195, 195.

12 H. I. Hamoud, B. Azambre and G. Finqueneisel, J. Chem. Technol. Biotechnol., 2016, 91, 2462.

13 E. Aneggi, V. Cabbai, A. Trovarelli and D. Goi, Int. J. Photoenergy, 2012, 2012, 694721.

14 C. M. Lousada, M. Yang, K. Nilsson and M. Jonsson, J. Mol. Catal. A: Chem., 2013, 379, 178.

15 T. S. Wu, Y. Y. Zhou, R. F. Sabirianov, W. N. Mei, Y. L. Soo and C. L. Cheung, Chem. Commun., 2016, 52, 5003.

16 S. M. Hirst, A. S. Karakoti, R. D. Tyler, N. Sriranganathan, S. Seal and C. M. Reilly, Small, 2009, 5, 2848.

17 W. D. Cai, F. Chen, X. X. Shen, L. J. Chen and J. L. Zhang, Appl. Catal., B, 2010, 101, 160.

18 S. Y. Hao, J. Hou, P. Aprea and F. Pepe, Appl. Catal., B, 2014, $160,566$.

19 F. H. Scholes, A. E. Hughes, S. G. Hardin, P. Lynch and P. R. Miller, Chem. Mater., 2007, 19, 2321.

20 E. Grulke, K. Reed, M. Beck, X. Huang, A. Cormack and S. Seal, Environ. Sci.: Nano, 2014, 1, 429.

21 P. F. Ji, L. Z. Wang, F. Chen and J. L. Zhang, ChemCatChem, 2010, 2, 1552.

22 F. Chen, X. X. Shen, Y. C. Wang and J. L. Zhang, Appl. Catal., $B, 2012,121,223$.

23 Z. M. Tian, J. Li, Z. Y. Zhang, W. Gao, X. M. Zhou and Y. Q. Qu, Biomaterials, 2015, 59, 116.

24 L. Artiglia, S. Agnoli, M. C. Paganini, M. Cattelan and G. Granozzi, ACS Appl. Mater. Interfaces, 2014, 6, 20130.

25 K. B. Zhou, X. Wang, X. M. Sun, Q. Peng and Y. D. Li, J. Catal., 2005, 229, 206.

26 T. Naganuma, Nano Res., 2017, 10, 199.

27 L. Wang, G. Lu, D. Yang, J. Wang, Z. B. Zhu, Z. X. Wang and K. B. Zhou, ChemCatChem, 2013, 5, 1308.

28 H. Y. Tan, J. Wang, S. Z. Yu and K. B. Zhou, Environ. Sci. Technol., 2015, 49, 8675.

29 T. S. Sreeremya, A. Krishnan, K. C. Remani, K. R. Patil, D. F. Brougham and S. Ghosh, ACS Appl. Mater. Interfaces, 2015, 7, 8545.

30 C. Zang, X. Zhang, S. Hu and F. Chen, Appl. Catal., B, 2017, 216, 106. 
31 Z. Yang, K. Zhou, X. Liu, Q. Tian, D. Lu and S. Yang, Nanotechnology, 2007, 18, 185606.

32 X. W. Liu, K. B. Zhou, L. Wang, B. Y. Wang and Y. D. Li, J. Am. Chem. Soc., 2009, 131, 3140.

33 D. Yang, L. Wang, Y. Z. Sun and K. B. Zhou, J. Phys. Chem. C, 2010, 114, 8926.

34 Y. Xue, Q. F. Luan, D. Yang, X. Yao and K. B. Zhou, J. Phys. Chem. C, 2011, 115, 4433.

35 J. E. Spanier, R. D. Robinson, F. Zheng, S. W. Chan and I. P. Herman, Phys. Rev. B: Condens. Matter Mater. Phys., 2001, 64, 245407.

36 W. H. Weber, K. C. Hass and J. R. McBride, Phys. Rev. B: Condens. Matter Mater. Phys., 1993, 48, 178.

37 A. Hiroki and J. A. LaVerne, J. Phys. Chem. B, 2005, 109, 3364. 38 Y. J. Wang, H. Dong, G. M. Lyu, H. Y. Zhang, J. Ke, L. Q. Kang, J. L. Teng, L. D. Sun, R. Si, J. Zhang, Y. J. Liu, Y. W. Zhang, Y. H. Huang and C. H. Yan, Nanoscale, 2015, 7, 13981.
39 E. G. Heckert, S. Seal and W. T. Self, Environ. Sci. Technol., 2008, 42, 5014.

40 L. J. Xu and J. L. Wang, Environ. Sci. Technol., 2012, 46, 10145.

41 P. Zhang, D. Sun, M. Wen, J. Yang, K. Zhou and Z. Wang, Adv. Synth. Catal., 2012, 354, 720.

42 R. N. McCormack, P. Mendez, S. Barkam, C. J. Neal, S. Das and S. Seal, J. Phys. Chem. C, 2014, 118, 18992.

43 A. D. Bokare and W. Choi, J. Hazard. Mater., 2014, 275, 121. 44 Y. C. Wang, X. X. Shen and F. Chen, J. Mol. Catal. A: Chem., 2014, 381, 38.

45 H. Zhao, Y. M. Dong, P. P. Jiang, G. L. Wang and J. J. Zhang, ACS Appl. Mater. Interfaces, 2015, 7, 6451.

46 S. H. Bossmann, E. Oliveros, S. Gob, S. Siegwart, E. P. Dahlen, L. Payawan, M. Straub, M. Worner and A. M. Braun, J. Phys. Chem. A, 1998, 102, 5542. 